\title{
Propuesta para optar por la modalidad de creación de empresa como alternativa de grado
}

\section{Proposal to opt for the graduation project modality of entrepreneurship}

\author{
Rafael Méndez \\ Director Centro de Emprendimiento e Innovación \\ Equipo de trabajo CEIN
}

El Centro de Emprendimiento e Innovación de la Universidad Surcolombiana, unidad adscrita a la Rectoría y creado por Acuerdo 004 de 2015 por el Consejo Superior, tiene la misión de "Promover y gestionar la cultura del emprendimientoy la innovación en la comunidad universitaria, a partir de la identificación y estructuración de ideas y proyectos de creación $\mathrm{y}$ fortalecimiento de iniciativas emprendedoras de carácter social, cultural, deportivas y empresariales, que conjuguen con un enfoque sistémico la investigación, el conocimiento, la interdisciplinariedad, la innovación y el emprendimiento de alto impacto para el crecimiento económico y social de la región y el país".

En cumplimiento de esa misión, uno de los objetivos específicos es el de "Complementar el proceso de formación profesional de los estudiantes en los diferentes programas académicos mediante la promoción y desarrollo de competencias emprendedoras, innovadoras y tecnológicas". Al explorar que venían haciendo las diferentes facultades de la Institución se encontró que en algunas existen acuerdos de consejos de facultad, que permiten la creación de empresas y la elaboración de planes de negocio como opción de grado.

Al examinar que están haciendo otras instituciones universitarias en esta temática y con la experiencia del Centro de Emprendimiento e Innovación, se elaboró un documento de trabajo como propuesta para las siete facultades de la Universidad, con el propósito de que este documento sea estudiado en cada Consejo de
Facultad y con las características particulares de cada una, sea ajustado y adoptado. De esta manera estaremos dando cumplimiento al fortalecimiento de la docencia, la investigación y la proyección social, mediante la articulación de estos ejes misionales de la Universidad con proyectos de emprendimiento innovador.

A continuación presentamos el documento de trabajo.

\section{MODALIDAD PROYECTO PARA CREACIÓN DE EMPRESA}

Artículo 1: Definiciones básicas.

- Empresa: Organización sostenible creada para la producción de bienes y/o servicios, con el propósito de atender las necesidades y expectativas de una población objetivo. La organización puede ser de carácter empresarial, social, cultural, ambiental o deportivo.

- Emprendimiento: "Manera de pensar y actuar orientado hacia la generación de riqueza. Es una forma de pensar, razonar y actuar centrada en las oportunidades, planteada con visión global y llevada a cabo mediante un liderazgo equilibrado y la gestión de un riesgo calculado, su resultado es la creación de valor que beneficia a la empresa, la economía y la sociedad". (Ley 1014 de 2006)

- Innovación: "Es la implementación de un producto (bien o servicio) nuevo o significativamente mejorado, un proceso, un método de mercadeo nuevo, o un método organizacional nuevo en las prácticas empresariales, la organización del trabajo o las relaciones externas". Manual de Oslo (OECD/ Eurostat, 2005) 
- Ciclo del proyecto: Secuencia de las fases de desarrollo de un proyecto conformado por Pre-inversión (idea, sector, concepto de negocio, oportunidad, perfil del proyecto, plan de negocio), inversión y Operación o Funcionamiento.

Artículo 2: La modalidad de creación de empresa tiene dos categorías: La primera relacionada con el desarrollo de una iniciativa que culmine en una propuesta de creación de empresa y la segunda consistente en el fortalecimiento o aceleración de una empresa propia o de carácter familiar mínimo con dos años de registrada en Cámara de Comercio en la que se pueda evidenciar la aplicación del conocimiento del área de formación del estudiante.

\section{CATEGORÍA I \\ DESARROLLO DE UNA INICIATIVA QUE CULMINE EN UNA PROPUESTA DE CREACIÓN DE EMPRESA}

Artículo 3: Requisitos.

- Los estudiantes que seleccionen esta modalidad deberán tener como mínimo el $60 \%$ de los créditos del plan de estudio aprobados.

- Los estudiantes interesados en esta modalidad de grado deberán certificar su participación en el curso "De la idea a la empresa" ofertado por el Centro de Emprendimiento e Innovación de la Universidad.

Artículo 4: Para la aprobación de esta modalidad de grado él o los estudiantes deberán presentar al respectivo Consejo de Facultad al cual está adscrito el Programa Académico, un perfil de la idea con base en la "Guía Metodológica para Argumentar la Idea" (Guía No 1 Centro de Emprendimiento e Innovación Versión 2).

Parágrafo 1: La idea debe estar relacionada con la aplicación del conocimiento de las respectivas disciplinas de formación profesional e incluir elementos con potencial innovador.
Parágrafo 2: La idea a desarrollar puede ser realizada de manera interdisciplinaria y según el origen disciplinar del o de los proponentes, la respectiva Facultad dará el aval de aprobación y asignará un tutor.

Parágrafo 3: En caso de que la idea sea desarrollada por estudiantes de diferentes disciplinas del conocimiento y se asigne un tutor por cada facultad, el Centro de Emprendimiento e Innovación ofrecerá la asesoría necesaria para asegurar la articulación, optimización y aporte de cada área del conocimiento.

Artículo 5: El o los estudiantes deberán presentar el perfil del proyecto de creación de empresa al Consejo de Facultad quien asignará los jurados para la evaluación y concepto de aprobación de grado.

Parágrafo 1: En caso de ser aprobado, los estudiantes deberán registrar el proyecto de creación de empresas en el Banco de Proyectos del Centro de Emprendimiento e Innovación.

\section{CATEGORIA II FORTALECIMIENTO O ACELERACIÓN DE UNA EMPRESA PROPIA O DE CARÁCTER FAMILIAR}

Artículo 6: Requisitos.

- Los estudiantes que seleccionen esta modalidad deberán tener como mínimo el 60\% de los créditos del plan de estudio aprobados.

- Los estudiantes deberán presentar el certificado de existencia y representación legal para constatar el tiempo de creación de la empresa.

Artículo 7: Para la aprobación de esta modalidad de grado él o los estudiantes deberán presentar una propuesta al Consejo de Facultad con base en la "Guía Metodológica para el fortalecimiento o aceleración" (Guía No 2 Centro de Emprendimiento e Innovación Versión 1).

Parágrafo 1: La propuesta debe estar relacionada con la aplicación del conocimiento de las respectivas disciplinas de formación 
profesional e incluir elementos con potencial innovador.

Parágrafo 2: La propuesta a desarrollar puede ser realizada de manera interdisciplinaria y según el origen disciplinar del o de los proponentes, la respectiva Facultad dará el aval de aprobación.

Parágrafo 3: El Centro de Emprendimiento e Innovación ofrecerá la asesoría y el acompañamiento necesario para la elaboración del proyecto.
Artículo 8: El o los estudiantes deberán presentar el proyecto de fortalecimiento o aceleración de empresa al Consejo de Facultad quien asignará los jurados para la evaluación y concepto de aprobación de grado.

Parágrafo 1: En caso de ser aprobado, los estudiantes deberán registrar el proyecto de fortalecimiento o aceleración de empresa en el Banco de Proyectos del Centro de Emprendimiento e Innovación. 